\title{
Application of Simplex Lattice Design in Watermelon Production
}

\author{
Dennis K. Muriithi \\ Faculty of Science, Engineering and Technology, Chuka University \\ P. O. Box 109-60400, Chuka Kenya \\ Correspondence Email: kamuriithi2011@gmail.com
}

\begin{abstract}
This paper discusses the use of Simplex Lattice Design approach to plan the experiment for yield of watermelon with an overall objective of optimizing the multiple responses of watermelon to organic manure. Multiple linear regression models have been adopted to express the output parameters (responses) that are decided by the input process parameters. Poultry manure, cow manure and goat manure were the independent variables to optimize the response values of interest that includes; watermelon fruit weight, number of fruits of watermelon per plant. Mixture experiments are appropriate to use when a researcher wishes to determine if synergism exists in mixing components which increases productivity. Three-component design presented in this study illustrated how to apply mixture designs in agricultural research. Mathematical Model evolved for response show the effect of each input parameter and its interaction with other parameters, depicting the trend of response. From, the equation of fruit weight and number of fruits, it can be concluded that goat manure has a more important role on watermelon production in the current study. Conclusively, the current study attained the optimal condition of $17.68 \mathrm{ton} / \mathrm{Ha}$, $11.69 \mathrm{ton} / \mathrm{Ha}$ and $19.16 \mathrm{ton} / \mathrm{Ha}$ of poultry manure, cow manure and goat manure respectively, would guarantee the farmer a maximum yield of $22.13 \mathrm{~kg}$ fruit weight of watermelon per plant and $7.74 \approx 8$ Fruit of watermelon per plant. The study exemplified that the development of statistical models for crop production can be useful for predicting and understanding the effects of experimental factors.
\end{abstract}

KEYWORDS: Fruit Weight; Watermelon; Model; Mixture Experiment; Simplex Lattice Design; Organic Manure

DOI: $10.7176 / \mathrm{MTM} / 9-1-09$

\subsection{INTRODUCTION}

Watermelon (Citrullus lanatus thumb) is a member of the cucurbitaceous family. According to [4], it originated from the Kalahari and Sahara deserts in Africa. In Kenya, the crop is mainly grown in lower and dry Semi-arid areas of the Country, namely Nyanza, Central, Coast and Rift Valley. Watermelon is a crop with huge economic importance to man as well as highly nutritious, sweet and thirst quenching [6]. It is mostly used to make a variety of salads, juice and food flavor. It is a cash crop for farmers due to its high returns on investment. Watermelon contains Vitamin $\mathrm{C}$ and $\mathrm{A}$ in a form of disease-fighting beta-carotene. Also, it contains potassium which helps in the control of blood pressure and possibly prevent stroke as suggested by [3]. In spite of the increasing relevance of watermelon in Kenya, yields across the country are decreasing and not encouraging because of rapid reduction in soil fertility caused by both continuous cropping and use of inappropriate soil amendment materials, [7]. One of the ways of increasing the soil fertility is by application of organic material such as poultry manure, cow manure, and goat manure which are available in most parts of the country. Animal waste is essential for establishing and maintaining the optimum soil physical, chemical and biological condition that are appropriate for plant growth and development. Although readily available, utilization of these organic manures in watermelons has not been optimized for increased plant growth and fruit production [7].

The design factors in a mixture experiment are the proportion of the components of a blend and the response variable vary as a function of these proportion making the total and not the actual quantity if each component. The total amount of mixture is normally fixed in a mixture experiment and the component settings are proportion of the total amount [1]. For instance if an experiment on crop yield due to various mixture of fertilizers the amount of fertilizer applied to the plots is allowed to vary, then the amount of applied can greatly affect the yield. If we fix the amount of applied fertilizer to be constant on all plots, then the fertilizer trials can be considered a mixture experiment because the crop yield per plot would be a function of ingredient proportions.

Mixture experiment has been applied in many fields such as Biological and Clinical Science and the process industries (chemical formulations, food processing among others), but not much application of the same has been done on Agriculture [5]. The purpose of this study was to fit an appropriate mathematical model to express response variables as functions of the proportions of the mixture components of organic manure and optimizes the multiple responses of watermelon to organic manure. 


\subsection{MATERIAL AND METHODS}

In experiments, different factors are considered while selecting designs so as to suit particular objectives. For example, a design with a small number of runs but gives enough information on the coefficients of the model developed would be preferred as far as cost is concerned. Another factor considered in the selection of a design is the prediction capability of the design. Scaled prediction variance has been suggested as a measure of prediction variance, [8].

\subsection{Experimental Design}

A Simplex Lattice Design was adopted to optimize control variables. In this design 3 factors were evaluated by changing their amount simultaneously and keeping total amount constant, [5].

Table 1: Actual Value of Coded Levels

\begin{tabular}{lccc}
\hline & \multicolumn{3}{c}{ Actual Values (Tonnes/Ha) } \\
\cline { 2 - 4 } Coded levels & $\boldsymbol{X}_{\boldsymbol{1}}$ & $\boldsymbol{X}_{\boldsymbol{2}}$ & $\boldsymbol{X}_{\mathbf{3}}$ \\
\hline 1 & 20 & 20 & 20 \\
0 & 17.3 & 13.3 & 18.1 \\
\hline
\end{tabular}

Poultry manure $\left(X_{1}\right)$, cow manure $\left(X_{2}\right)$ and goat manure $\left(X_{3}\right)$ were the independent variables to optimize the response value of interest (fruit weight of watermelon at maturity, number of Fruit of watermelon per plant). The Simplex Lattice using all possible blends of these three components shows 10 different mixtures for $\{3,3\}$ design. These design points are the blending coordinates arranged such that all combinations of factor level are tested. The sum for each run of the mixture is one and the component values are interpreted as proportions. The statistical design is referred to as $\{3,3\}$ simples lattice design as shown in Table 2.

Table 2: Simplex Lattice design for $0,1 / 3,2 / 3$ and 1 designated as $\{3,3\}$ design situation

\begin{tabular}{lcccl}
\hline & \multicolumn{3}{c}{$\mathbf{3 , 3}$} Simplex Lattice Design & \\
\cline { 2 - 4 } Run & $\mathbf{X}_{\mathbf{1}}$ & $\mathbf{X}_{\mathbf{2}}$ & $\mathbf{X}_{\mathbf{3}}$ & \\
\hline 1 & 1 & 0 & 0 & Permutations \\
2 & 0 & 1 & 0 & Single-component blend \\
3 & 0 & 0 & 1 & Single-component blend \\
4 & $1 / 3$ & $2 / 3$ & 0 & Single-component blend \\
5 & $1 / 3$ & 0 & $2 / 3$ & Binary-component blend \\
6 & 0 & $1 / 3$ & $2 / 3$ & Binary-component blend \\
7 & $2 / 3$ & $1 / 3$ & 0 & Binary-component blend \\
8 & $2 / 3$ & 0 & $1 / 3$ & Binary-component blend \\
9 & 0 & $2 / 3$ & $1 / 3$ & Binary-component blend blend \\
10 & $1 / 3$ & $1 / 3$ & $1 / 3$ & Multi-component blend \\
\hline
\end{tabular}

\subsection{Mathematical Models}

The second- order model representing the watermelon fruit Weight at maturity was expressed as a function of Poultry manure, cow manure and goat manure being in the input variable of watermelon responses. To define the response equation, $X_{1}, X_{2}$ and $X_{3}$ are assigned to poultry manure, cow manure and goat manure respectively. An appropriate polynomial (second-order) models can be expressed as;

$$
\begin{aligned}
& Y_{1}=\alpha_{1} X_{1}+\alpha_{2} X_{2}+\alpha_{3} X_{3}+\alpha_{12} X_{1} X_{2}+\alpha_{13} X_{1} X_{3}+\alpha_{23} X_{2} X_{3} \\
& Y_{2}=\beta_{1} X_{1}+\beta_{2} X_{2}+\beta_{3} X_{3}+\beta_{12} X_{1} X_{2}+\beta_{13} X_{1} X_{3}+\beta_{23} X_{2} X_{3}
\end{aligned}
$$

Where $Y_{i}(i=1,2)$ is the predicted responses ( $1=$ Fruit Weight: $2=$ Number of Fruits), $X_{i}$ represent the control factors in the experimental data, $\alpha_{i}$ and $\beta_{i}$ is the linear coefficient and $\alpha_{i j}$ and $\beta_{i j} i$ s the cross-product coefficient (For $i=1,2,3 ; j=2,3$ and $i<j$ ). Simple lattice data was analyzed by help of Design Expert version 10 and R-Gui statistical soft wares. 


\subsection{Analysis of Variance}

ANOVA is a statistical decision-making tool used for detecting any differences in average performance of tested parameters [7]. It employs the sum of squares and F-statistic to find out the relative importance of the analyzing process parameter, measurement errors and uncontrolled parameters. It was used to check the adequacy of the model for the response in the experimentation.

\subsection{Data Source}

Data was obtained from an experiment carried out at horticultural research and teaching farm of Chuka University. A land measuring 448 meters squared $(28 \mathrm{M}$ by16 M) was selected for the study and prepared for planting. Ten (Run) plots of $4 \mathrm{M}$ by $3 \mathrm{M}$ each was made and composite samples collected from the plots at $0-15$ $\mathrm{cm}$ depth in order to assess the initial physical-chemical properties of the soil. The composite soil samples collected from individual plots was analyzed in the laboratory to determine initial physical-chemical properties of soils for the study. Similarly, the chemical analysis of poultry, goat and cow manure used for the experiment was evaluated using appropriate method. Each plot had 3 seeds per stand at a depth of $3 \mathrm{~cm}$, using a spacing of $200 \mathrm{~cm}$ by $100 \mathrm{~cm}$, with $100 \mathrm{~cm}$ Alley pathways. Data on watermelon fruit Weight at maturity was collected. Sukari F1 watermelon a newly developed variety from East Africa Seed Company was used in the study.

\subsection{RESULTS AND DISCUSSION}

Table 3: Design Matrix of Independent and Dependent Variables

\begin{tabular}{l|ccc|cc}
\hline \multirow{2}{*}{ Run } & \multicolumn{3}{|c|}{$\begin{array}{c}\text { Coded levels of } \\
\text { independent variables }\end{array}$} & \multicolumn{2}{c}{$\begin{array}{c}\text { Response Variable } \\
\text { (Dependent Variables) }\end{array}$} \\
\cline { 2 - 6 } & $\mathbf{X}_{\mathbf{1}}$ & $\mathbf{X}_{\mathbf{2}}$ & $\mathbf{X}_{\mathbf{3}}$ & Fruit Weight (Tonnes/Ha) & Number of Fruit \\
\hline 1 & 1 & 0 & 0 & 72 & 7 \\
2 & 0 & 1 & 0 & 46 & 7 \\
3 & 0 & 0 & 1 & 76 & 5 \\
4 & $1 / 3$ & $2 / 3$ & 0 & 48 & 4 \\
5 & $1 / 3$ & 0 & $2 / 3$ & 66 & 6 \\
6 & 0 & $1 / 3$ & $2 / 3$ & 54 & 7 \\
7 & $2 / 3$ & $1 / 3$ & 0 & 56 & 7 \\
8 & $2 / 3$ & 0 & $1 / 3$ & 48 & 6 \\
9 & 0 & $2 / 3$ & $1 / 3$ & 58 & 76 \\
10 & $1 / 3$ & $1 / 3$ & $1 / 3$ & & \\
\hline
\end{tabular}

Table 3 shows all results expressed as mean \pm standard deviation for four watermelon plants in each plot. To determine the effect of treatment, data was analyzed using one way analysis of variance repeated measures. Pvalues of less than 5\% were regarded as significant. Data was analyzed using the statistical package (R-Gui and Design Expert version 10). Experimental values were analyzed to get regression model.

Table 4: The Goodness -of -Fit of Models

\begin{tabular}{l|c|c}
\hline \multirow{2}{*}{ Statistics } & \multicolumn{2}{|c}{ Model } \\
\cline { 2 - 3 } & Fruit weight/Plant & Number of Fruits \\
\hline Std. Dev. & 0.572 & 0.1573 \\
Mean & 21.111 & 7.13 \\
C.V.\% & 2.71 & 2.21 \\
$\mathrm{R}^{2}$ & 0.875 & 0.975 \\
Adjusted R $^{2}$ & $\mathbf{0 . 8 2 9}$ & $\mathbf{0 . 9 2 4 9}$ \\
Adeq. Precision & 12.85 & 14.085 \\
\hline
\end{tabular}

Model summary statistics focus on the model maximizing the adjusted R-Squared. Adjusted R-Squared is used to adjust the statistic based on the number of independent variables in the model. It compares the explanatory power of regression model that contains different independent predictors. In this case, since the multiple regression models have more than one variable, Adjusted R-Squared is the most preferred. The study found that adjusted coefficient of determination is 0.83 . It implies that $83 \%$ of the variability in the response variable is accounted for by the predictors (Organic Manure) in the model. Similarly, the study found that adjusted coefficient of determination is 0.925 . It implies that $92.5 \%$ of the variability in the response variable is explained by the predictors (Organic Manure) in the model. The adjusted R-squared is often used to summarize the fit as it 
takes into account the number of variables in the model. In this study, quadratic model is considered fit for prediction of the fruit weight and number of fruit of watermelon plant using organic manure.

Table 5: The Individual Significance in the Models

\begin{tabular}{l|ccc|ccc}
\hline \multirow{2}{*}{ Component } & \multicolumn{3}{|c|}{ Fruit Weight } & \multicolumn{3}{c}{ Number of Fruits } \\
\cline { 2 - 7 } & $\begin{array}{c}\text { Coefficient } \\
\text { Estimate }\end{array}$ & $\begin{array}{c}\text { Standard } \\
\text { Error }\end{array}$ & P-Values & $\begin{array}{c}\text { Coefficient } \\
\text { Estimate }\end{array}$ & $\begin{array}{c}\text { Standard } \\
\text { Error }\end{array}$ & P-values \\
\hline$X_{1}$ & 18.72 & 0.5018 & 0.0358 & 6.59 & 0.1496 & 0.0257 \\
$X_{2}$ & 16.78 & 0.5018 & 0.0358 & 5.84 & 0.1496 & 0.0257 \\
$X_{3}$ & 19.89 & 0.5018 & 0.0358 & 6.96 & 0.1496 & 0.0257 \\
$X_{I} X_{2}$ & 12.95 & 2.35 & 0.0112 & 5.20 & 0.6993 & 0.005 \\
$X_{I} X_{3}$ & 13.16 & 2.35 & 0.0117 & 4.62 & 0.6993 & 0.0071 \\
$X_{2} X_{3}$ & 11.19 & 2.35 & 0.0175 & 3.83 & 0.6993 & 0.0119 \\
\hline
\end{tabular}

The effect of the variable as linear, quadratic or interaction coefficient on the response was tested for significance. The study found that poultry, cow and goat manure were statistically significant at $5 \%$ significance level with P-value of each type of manure of $0.0358<0.05$ and $0.0257<0.05$ for fruit weight and number of fruits of watermelon respectively. The regression coefficient estimates show that for one unit change in poultry manure, cow manure and goat manure, fruit weight of watermelon would increase by a factor of 18.72, 16.78 and 19.89 respectively. This implies that goat manure is slightly more effective than poultry manure on fruit weight of watermelon plant. In addition, it was found that combined application of poultry and goat manure had a regression coefficient value of 13.16 and a $\mathrm{P}$-value of $0.0117<0.05$, hence statistically significant at $5 \%$ significance level. This implies that for one unit change in combined poultry and goat manure $\left(X_{1} X_{3}\right)$, fruit weight of watermelon plant would increase by a factor of 13.16. Similarly, the regression coefficient estimates show that for one unit change in poultry manure, cow manure and goat manure, number of fruit of watermelon would increase by a factor of $6.59,5.84$ and 6.96 respectively. This implies that goat manure is slightly more effective than poultry manure on number of fruit of watermelon plant. The adjusted models obtained for fruit weight and number of fruit of watermelon plant as a function of the significant variables is stated as follows.

$$
\begin{aligned}
& Y_{1}=18.72 X_{1}+16.78 X_{2}+19.89 X_{3}+12.95 X_{1} X_{2}+13.16 X_{1} X_{3}+11.19 X_{2} X_{3} \\
& Y_{2}=6.590 X_{1}+5.840 X_{2}+6.960 X_{3}+5.200 X_{1} X_{2}+4.620 X_{1} X_{3}+3.830 X_{2} X_{3}
\end{aligned}
$$

Where $Y_{i}(i=1,2)$ is the predicted response ( $1=$ Fruit Weight; $2=$ No. of Fruit), $X_{i}(i=1,2,3)$ represent the control factors in the experimental data ( $1=$ Poultry manure; $2=$ Cow manure; $3=$ Goat manure).

\begin{tabular}{|c|c|c|c|c|c|c|c|c|c|c|}
\hline \multirow[b]{2}{*}{ Source } & \multicolumn{5}{|c|}{ Fruit Weight } & \multicolumn{5}{|c|}{ Number of Fruits } \\
\hline & $\begin{array}{c}\text { Sum of } \\
\text { Squares }\end{array}$ & df & $\begin{array}{c}\text { Mean } \\
\text { Square }\end{array}$ & $\begin{array}{c}\text { F- } \\
\text { value }\end{array}$ & P-value & $\begin{array}{c}\text { Sum of } \\
\text { Squares }\end{array}$ & df & $\begin{array}{c}\text { Mean } \\
\text { Square }\end{array}$ & $\begin{array}{c}\text { F- } \\
\text { value }\end{array}$ & p-value \\
\hline Model & 22.29 & 6 & 3.72 & 13.35 & 0.0287 & 2.89 & 6 & 0.482 & 19.48 & 0.0168 \\
\hline $\begin{array}{l}\text { Linear } \\
\text { Mixture }\end{array}$ & 6.85 & 2 & 3.42 & 12.31 & 0.0358 & 0.78 & 2 & 0.3888 & 15.72 & 0.0257 \\
\hline $\mathrm{X}_{1} \mathrm{X}_{2}$ & 8.75 & 1 & 8.75 & 31.46 & 0.0112 & 1.37 & 1 & 1.37 & 55.25 & 0.005 \\
\hline $\mathrm{X}_{1} \mathrm{X}_{3}$ & 8.48 & 1 & 8.48 & 30.46 & 0.0117 & 1.08 & 1 & 1.08 & 43.57 & 0.0071 \\
\hline $\mathrm{X}_{2} \mathrm{X}_{3}$ & 6.34 & 1 & 6.34 & 22.77 & 0.0175 & 0.74 & 1 & 0.74 & 30.04 & 0.0119 \\
\hline Residual & 0.84 & 3 & 0.2783 & & & 0.07 & 3 & 0.02 & & \\
\hline Cor Total & 23.13 & 9 & & & & 2.97 & 9 & & & \\
\hline
\end{tabular}

Table 6: The Overall Significance of Models

This study found that the models can be considered statistically significant according to the F-test at 5\% level of significance, as the F-value of 13.35 and 19.48 are higher than F $(6,3)=8.94$. Since the P-value of 0.0287 and 0.0168 were less than $5 \%$, it implies that the models are statistically significance. Therefore, the hypothesis that there is no quantifiable effect of poultry, cow and goat manure on the fruit weight and number of fruits of watermelon plant is not supported by the current study. The study concludes that the quadratic models were adequate for prediction purpose. 


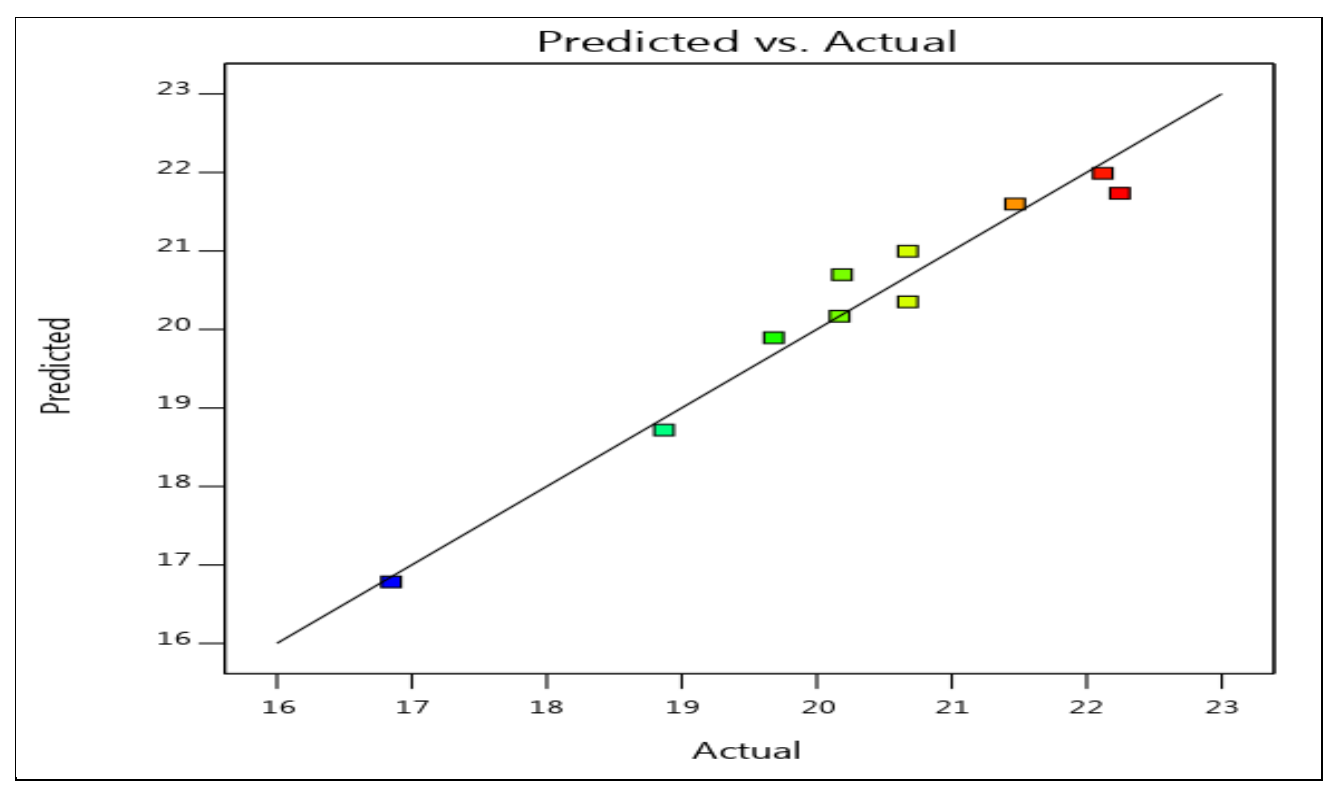

Figure 1: Predicted Value vs Experimental Value of fruit weight of Watermelon

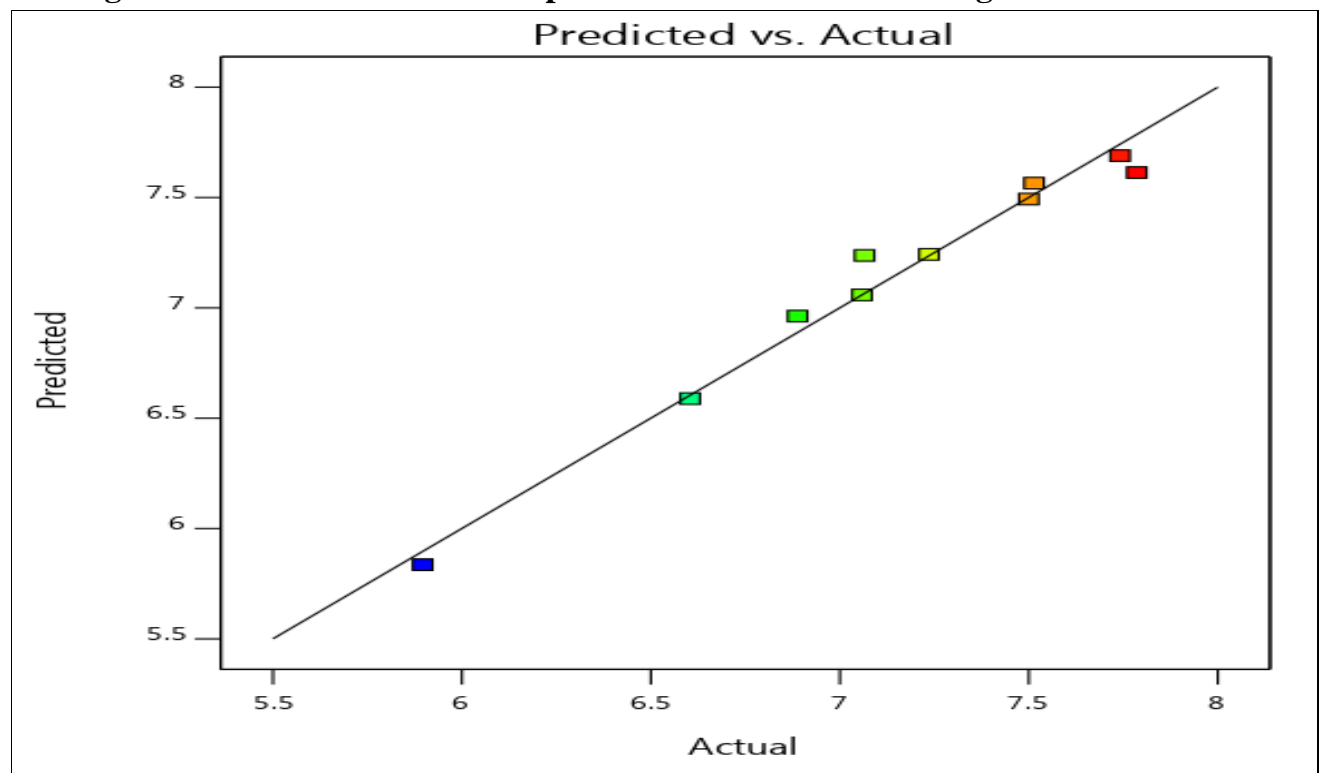

Figure 2: Predicted Value vs Experimental Value of No. of fruit of Watermelon

The line of the best fit is plotted taking the predicted value on $y$-axis and experimental value on $\mathrm{x}$-axis and is considered as a reference line. Experimental values of each response are plotted and their closeness to the line of the best fit depicts the accuracy (fitness) of the model. The models developed for the response are considered accurate, where all the measured-values are aligning or closer with the line of the best fit. 


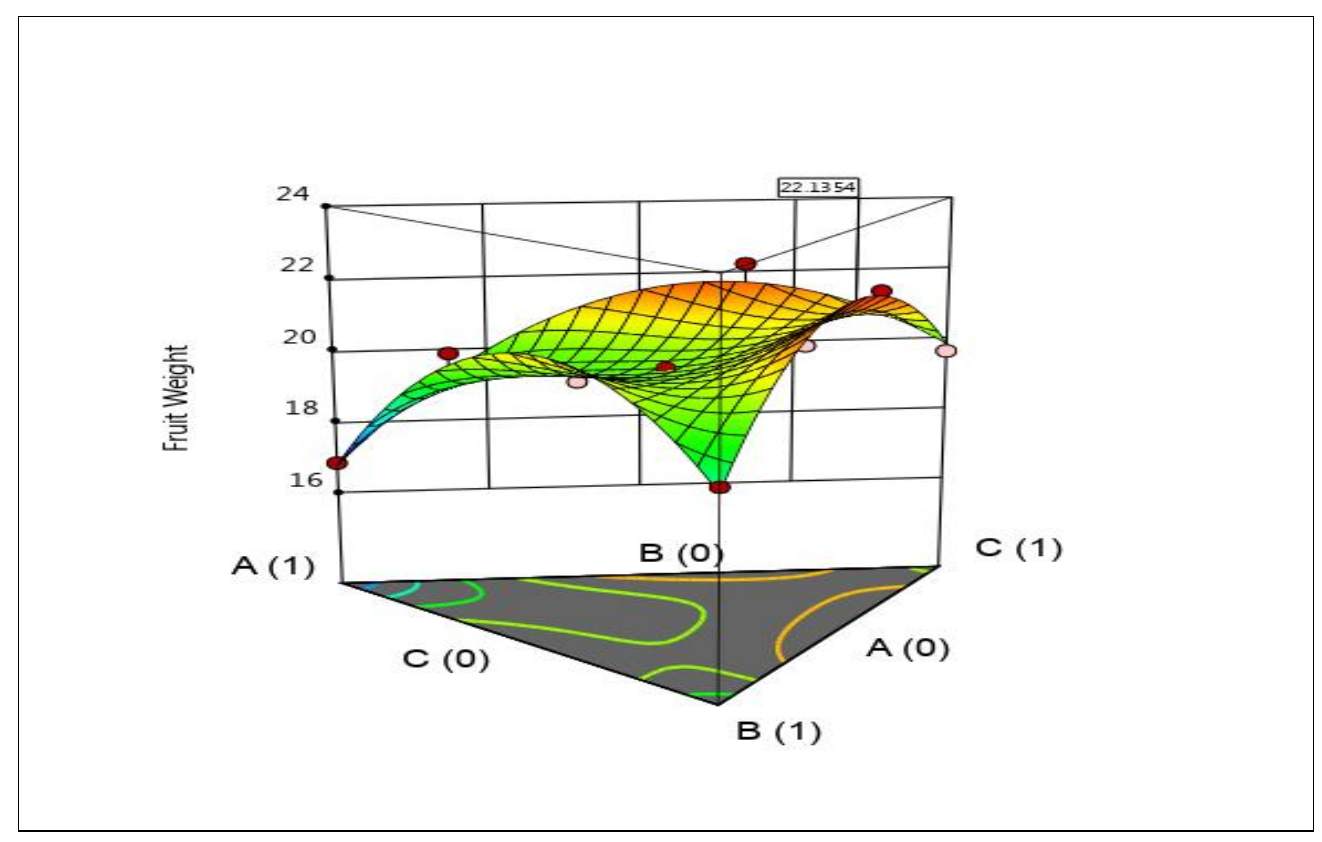

Figure 3: Response surface plot for Fruit weight of Watermelon

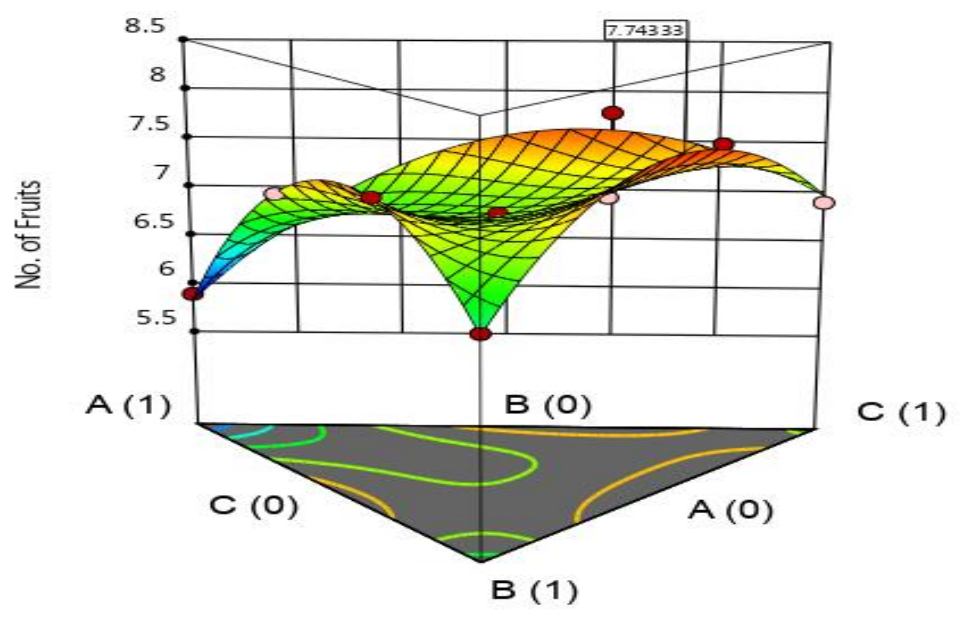

\section{Figure 4: Response surface plot for Number of fruits of Watermelon}

The graphical visualization is very helpful in understanding the quadratic model response surface. Figures 3 and 4 display plots of 3-dimension (3D) for different combination of variables (poultry, cow and goat manure) which exhibit the trend of variation of response (fruit weight and number of fruits) within the selected range of input variables and also influence of each variable over the other variable. The equation for fruit weight suggests that the factor Goat manure (C) has more significant effect on fruit weight and number of fruits of watermelon. From the equation of fruit weight and number of fruits, it can be concluded that goat manure (C) has a more important role on watermelon production. These types of plots are useful in study of the effects of three factors on the response at one time. The study found that the optimal condition of $17.68 \mathrm{ton} / \mathrm{Ha}, 11.69 \mathrm{ton} / \mathrm{Ha}$ and 19.16 ton/Ha of poultry manure, cow manure and goat manure respectively would yield a maximum of $22.13 \mathrm{~kg}$ fruit weight of watermelon per plant and $7.74 \approx 8$ Fruit of watermelon per plant. 


\subsection{CONCLUSION}

Mixture experiments are appropriate to use when a researcher wishes to determine if synergism exists in mixing components which increases productivity. Three-component design presented in this study illustrated how to apply mixture designs in agricultural research. Mathematical Model evolved for response show the effect of each input parameter and its interaction with other parameters, depicting the trend of response. From, the equation of fruit weight and number of fruits, it can be concluded that goat manure has a more important role on watermelon production in the current study. Conclusively, the current study attained the optimal condition of $17.68 \mathrm{ton} / \mathrm{Ha}$, $11.69 \mathrm{ton} / \mathrm{Ha}$ and $19.16 \mathrm{ton} / \mathrm{Ha}$ of poultry manure, cow manure and goat manure respectively would guarantee the farmer a maximum yield of $22.13 \mathrm{~kg}$ fruit weight of watermelon per plant and $7.74 \approx 8$ Fruit of watermelon per plant. The study exemplified that the development of statistical models for crop production can be useful for predicting and understanding the effects of experimental factors.

\subsection{ACKNOWLEDGEMENT}

The author is grateful to the research and publication office of Chuka University for the financial support. The author is thankful to Prof. J.Koske and Dr. G. Gathungu for their support and guidance towards the completion of this study.

\subsection{REFERENCES}

[1]Claringbold, P.J. Use of the simplex design in the study of the joint action of related hormones. 1955

[2] Enujeke E.C. Response of Watermelon to Five different rate of Poultry Manure, IOSR-JAVS, 2013, Vol 5(2), PP 45-50 (www.iosrjournals.org)

[3]IITA. Growing watermelon commercially in Nigeria- an illustrated guide. International Institute of Tropical Agriculture (IITA), 2013, 1-16

[4]Jarret, B., R. Bill, W. Tom and A. Garry. Cucurbits Germplasm Report, 1996, pp: 29-66. Watermelon National Germplasm System, Agricultural Service, U.S.D.A.

[5]Mandlik Satish K, Adhikari Saugat, Deshpande Ameya A. Application of Simplex Lattice Design in Formulation and Development of Buoyant Matrices of Dipyridamole. Journal App Pharm Sci. 2012; 2 (12): 107-111.

[6]Mangila, E., Tabiliran, F.P., Naguit., M.R.A and Malate, R. Effects of Organic Fertilizer on the Yield of Watermelon, Threshold, 2007, Vol. 2; 27-35

[7]Muriithi, D.K, J. K. Arap Koske, Geofrey K. Gathungu. Application of Central Composite Design Based Response Surface Methodology in Parameter Optimization of Watermelon Fruit Weight Using Organic Manure. American Journal of Theoretical and Applied Statistics, Vol. 6, No. 2, 2017, pp. 108-116. doi: 10.11648/j.ajtas.20170602.16

[8]Muriithi, D.K.. The Optimization of Multiple Responses of Watermelon to Organic Manure Using Response Surface Methodology, European International Journal of Science and Technology, 2017, Vol. 6(2):52-70

[9]Muriithi, D. K. Application of Response Surface Methodology for Optimization of Potato Tuber Yield. American Journal of Theoretical and Applied Statistics, 4(4) (2015), pp. 300-304. doi: 10.11648/j.ajtas.20150404.20 